Article

\title{
Implementation of Water-Saving Measures in Hotels in Mallorca
}

\author{
Dolores Tirado $^{1}$, William Nilsson ${ }^{1}$, Bartolomé Deyà-Tortella ${ }^{2}$ and Celso García ${ }^{3, *([)}$ \\ 1 Department of Applied Economics, University of the Balearic Islands, 07122 Palma, Spain; \\ dolores.tirado@uib.es (D.T.); william.nilsson@uib.es (W.N.) \\ 2 Department of Business Economics, University of the Balearic Islands, 07122 Palma, Spain; tolo.deya@uib.es \\ 3 Department of Geography, University of the Balearic Islands, 07122 Palma, Spain \\ * Correspondence: celso.garcia@uib.es; Tel.: +34-971172793
}

Received: 4 November 2019; Accepted: 2 December 2019; Published: 3 December 2019

check for updates

\begin{abstract}
The efficient management of water resources by the tourism sector is essential to be able to achieve sustainability in the future. Hotels, together with other tour operators, have a responsibility not to use more water than is absolutely necessary. Through a survey carried out in hotels on the island of Mallorca, we asked hotel managers about their water consumption and what types of water-saving measures they had introduced. We identified eleven water-saving measures, which were classified into "advanced" and "simple" according to the technical complications and the level of economic investment required. The numbers of measures of each kind that had been implemented were used as the dependent variables in two different Ordered Probit models. This method allowed us to identify the main variables that explain the introduction of water-saving measures. The significant main variables leading hotel managers to adopt simple water-saving initiatives are the existence of laundry facilities, the age of the hotel, and the number of stars. The same variables were found to be important for the introduction of advanced measures. The main drivers for introducing water-saving measures were the reduction in costs, followed by environmental concerns, while legal requirements and customer loyalty were found to be the least important drivers.
\end{abstract}

Keywords: water-saving measures; Mallorca; hotel water consumption; tourism sustainability

\section{Introduction}

The tourism sector has increased significantly in recent years, and is the industry that has grown the most in the world. According to the World Tourism Organization, the number of tourists was 1329 million worldwide in 2017, concentrated largely in regions with water scarcity, such as islands and coastal areas [1]. Forecasts suggest that this growth will continue in the future, reaching 1800 million people in 2030 [2] (p.35). In this context, the sustainable management of water resources in tourist destinations becomes a key element.

Tourism requires a significant increase in the demand for water to cover drinking water and hygiene needs. For example, the hotel industry uses large quantities of fresh water to clean towels and linens [3]. Fresh water is also needed for recreational and sports activities, such as in water parks, swimming pools, golf courses, and rivers. Additionally, the tourism industry gives rise to an indirect increase in water consumption in other economic sectors that produce goods or services which form part of the tourism supply chain (agriculture, services, gardening, etc.) [4,5]. Thus, the sum of both types of consumption means that a tourist's water consumption, in per capita terms, is much higher than that of a resident's consumption. It can, in fact, be double or triple in developed countries [6,7] or up to fifteen times higher in developing countries [8]. 
Moreover, tourists are quite sensitive to water quality and the reliability of the supply, and demand standards that are higher than those normally expected by residents [9] (p. 52). The quality of both fresh and sea water has become a significant factor in the choice of tourist destination [10] (p. 32). Many of the traditional coastal destinations with tourist attractions have problems of water scarcity as a result of reduced rainfall, such as in regions with an arid climate. Some destinations have problems due to the irregular distribution of water between different months or from one year to another, as occurs for instance in regions with a Mediterranean climate.

The efficient management of water resources by the tourism sector is therefore essential to achieve its sustainability in the future $[11,12]$. If we take into account the fact that hotels are the most popular accommodation option among tourists and tend to present the highest water consumption levels among the different lodging categories (campsites, holiday lets, bed \& breakfast guesthouses, etc.) [13], then the efficient and sustainable use of water by the hotel industry will be a key issue for the coming decades [14]. The high levels of water consumption by hotels have been documented in previous studies. Thus, for example, the estimated European average water consumption in such establishments is around 394 L/g.n. (per guest per night) [13]. Hotels in Barbados have an average water consumption of 839 L/g.n. [15], the average consumption of hotels in the Australia and New Zealand region is 313 L/g.n., while in the region of Hong Kong, Singapore, Indonesia, and Thailand, the average is 677 L/g.n. [16].

In this context, the main objective of this study is to analyze the level of implementation of water-saving measures in the hotel sector and to identify, by applying an Ordered Probit model, the main variables that drive their adoption. The study provides new evidence from one of the main tourist destinations in the Mediterranean Sea, the island of Mallorca (Spain). From a survey addressed to hotel managers on the island, we obtained data related to the physical and organizational characteristics of the hotel (i.e., size, stars, chain affiliation, etc.), their water consumption, and the water-saving measures introduced in recent years.

\section{Materials and Methods}

\subsection{Study Area}

The island of Mallorca is the largest and most populated island of the Balearic archipelago, located in the Mediterranean Sea off the east coast of the Iberian Peninsula (see Figure 1). The island has a typical Mediterranean climate, with hot dry summers and mild winters. Rainwater is highly unpredictable and variable between months (with $60 \%$ of the annual rainfall concentrated between October and January) and years (causing cyclical droughts). The calcareous lithology of the island causes the infiltration of water and of any temporary streams and, consequently, the lack of important surface water courses. Thus, groundwater is the main natural source of raw water $(73 \%$ of the total water supply).

Urban consumption accounts for $54 \%$ of the total water consumption and includes not only the water consumed by residents, but also that consumed by tourists in their lodging place, and the water used in different services and activities that are part of the tourist experience (i.e., bars, restaurants, etc.). With a resident population of 868,693 inhabitants in 2017 and 15 times as many tourists (13.8 million tourists [17]), Mallorca is one of the Spanish regions where the weight of water consumption by tourism is the highest and it also obtains the highest equivalent tourist population in Spain.

The tourists that visit the island mainly embrace the traditional combination of the sun and the beach. This is a model of mass tourism with a high seasonal component, concentrated during the period June-September ( $63 \%$ of the total). Hotels are the most common form of accommodation among tourists (67\%) and account for up to 45.01 million overnight stays-the highest number in Spain.

The increasing water demand, together with the pronounced seasonality in tourist arrivals and the limited water resources, have put the island's water resources under a large amount of pressure and have led to severe problems of overexploitation $[4,5,18,19]$. 


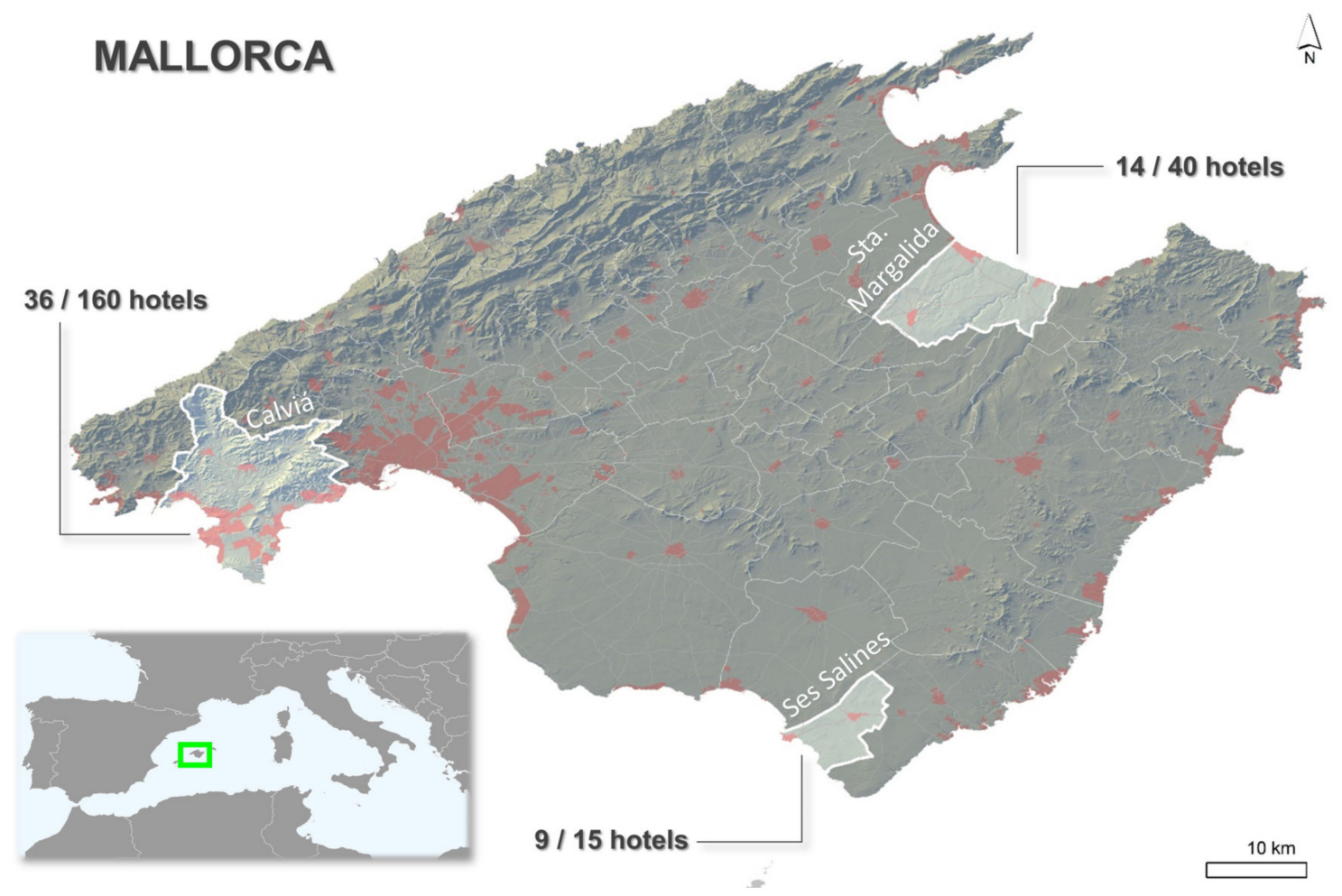

Figure 1. Location of the three municipalities on the island of Mallorca and number of hotels used in the study. Source: own elaboration using ESRI ArcGIS ®.

The hotel sector of the island of Mallorca provides a world benchmark in economic and tourism management (the island houses the headquarters of four of the 50 largest hotel chains in the world: Melia Hotels International, Riu Hotels and Resorts, Barceló Hotel Group, and Iberostar Hotels and Resorts). In this context, it is crucial to determine what measures have been implemented to guarantee the sustainability of the local water resources.

\subsection{Sample}

Three representative tourist municipalities of the island were selected for this study: Calvià, Ses Salines, and Santa Margalida, in south-western, south-eastern, and north-eastern Mallorca, respectively (see Figure 1). All three municipalities are coastal regions and their hotel plants, representative of the sun-and-sand market segment, offer a total of 64,450 beds, which is $27.2 \%$ of the total hotel availability in Mallorca.

The database was obtained through a survey carried out in September 2017 among an initial representative sample (based on hotel category) of 93 hotels in the three municipalities. The survey included information related to the physical characteristics of the hotel (i.e., its age, number of rooms, spa or laundry facilities, pool area), the hotel management system (i.e., belonging to a chain, number of stars), the hotel's level of water consumption per overnight stay, and the water-saving measures introduced in recent years (from a list of 11 options) to reduce the amount of water consumed. In addition, several questions were included in order to identify the main drivers underlying the introduction of such measures.

The survey contains four continuous sum questions for percentages, 12 closed-ended survey questions for quantitative discrete responses, one closed-ended survey question for a qualitative ordinal response, and three closed-ended survey questions with yes/no options and a specification if the respondent answers yes. In addition to these questions, four multiple-choice questions were included, where three have a closed-ended option for "other". Survey questions where the answer could vary over time covers specifications for all of the years 2011-2015. One of the closed-ended survey 
questions for a quantitative discrete response (i.e. occupancy rate in \%) covers monthly specification. A translated version of the complete survey is included in the Supplementary Materials (S1).

The questionnaire was answered directly by the hotel managers during a series of interviews conducted by the researchers. Some hotel managers had difficulty in answering some of the questions, and in some cases the problem of missing data arose. For this reason, data related to hotel water consumption indicators was complemented with information provided by water management companies. The imputation method was not applied. Thus, the final dataset included 59 hotels, which represents $27.2 \%$ of the total hotel plant in the three municipalities, and was representative (based on hotel category) of the total population. This reduced response rate by hoteliers, when asked about issues related to water consumption, is common in the literature $[15,20,21]$. Thus, the response levels obtained (almost two thirds of the initial sample and $27.2 \%$ of all the hotels in the area) can be considered a fairly good coverage in this field.

The sample is composed of a set of mature hotels, with an average age of 47.2 years, and an average size of 184 rooms. This typology is common in the Balearic Islands, and on the island of Mallorca in particular, as it was one of the pioneering sun-and-sand mass tourism destinations in Europe in the sixties and seventies. Thus, an important part of our hotel plant is characterized by advanced ages and significant hotel sizes (in order to exploit the benefits of the mass tourism model, mostly concentrated during the summer months).

Of the total number of hotels in the sample, $44.1 \%$ have spa facilities in the hotel premises, and $49.2 \%$ have laundry facilities. The average pool area of a hotel is around 235.2 square meters. With respect to the management characteristics, $74.6 \%$ of the hotels belong to a chain, and the most common hotels are four and three stars, which represent $52.5 \%$ and $37.3 \%$ of the sample, respectively.

\subsection{Methods}

The main objective of the study is to detect and analyze the potential variables that influence the degree of adoption of water-saving measures. The study applied an Ordered Probit model. This method allowed us to identify the main variables that are related to water-saving measures introduced in the hotels.

In line with reference [22], the water-saving measures were classified as basic and advanced. The first, basic water-saving measures, do not require major technical complexity or, in general, a high economic investment. Some can be implemented without disrupting the normal operation of the hotel and without any inconvenience to guests, and can achieve significant reductions in water and energy consumption. According to various studies, the payback period for this type of investment is usually between two months and three years $[12,15,23]$. There are many examples of these kinds of water-saving measures: flow restrictor and aerators on faucets, maintenance of plumbing fixtures and devices, sink stoppers that seal properly, low-flow showerheads, water displacement toilet devices, short-flush valves, double push in the toilet flushes, washing control and the use of savings programs in washing machines, gardens with native vegetation, paving of outdoor areas, detailed control of water consumption, awareness and motivation of hotel guests and staff, linen and towel reuse programs, sweeping pool decks before rinsing with a hose, filtering the pool properly, irrigation of lawns in the early hours of the morning, efficient dishwaters, waterless thawing, etc.

The second kind of measures, advanced water-saving measures, require a significant economic investment and advanced knowledge and technical advice. The recovery period is usually more than three years, although the water savings are also greater than those obtained by basic water-saving innovations. Among these we find the control of water losses in the water supply and distribution network, monitoring and metering water in different departments or areas, optimization of irrigation systems in gardens (dripping, timers depending on weather conditions, etc.), reuse of gray water for toilet flushing or for irrigation, recycled water (from the laundry, kitchen, air conditioning condensate, pool backwash, or chilling tower blow-down water) for irrigation, installation of ozone systems in the laundry, rainwater collection and use for irrigation and toilet flushing, replacement of air-based 
cooling equipment by condensation equipment, installation of pressure regulators in the main water intake areas, swimming pools with seawater, etc.

First, and based on the findings of previous literature, we identify the most common water-saving measures introduced by hotels over the last few decades [11-13,15,16,22,24-29]. Then, following reference [22], we divide the different measures identified into two main sets, that is, simple and advanced innovations (see Table 1). This classification is based on the technical complications and the level of economic investment required for the introduction of each measure. We define "simple measures" as those that involve fewer technical problems and usually require a reduced investment for the hotel. Hence, in this category we include: introduction of low-flow fittings, infrared taps, low-flush toilets, efficient water devices in kitchens, efficient irrigation systems, and the introduction of vegetation with lower water requirements in gardens and green areas.

Table 1. Description of water-saving measures.

\begin{tabular}{|c|c|}
\hline \multicolumn{2}{|r|}{ Simple Measures } \\
\hline Low-flow fittings & Faucet aerators and water restrictors in showerheads and taps, new low-flow devices \\
\hline Infrared taps & Hands-free faucets with a sensor that contains a light emitting diode (LED) \\
\hline Low-flush toilets & Toilets with dual flush option or cistern volume-adjusting devices, new low-flow devices \\
\hline Efficient devices in kitchens & Lower-flow taps with pedal, efficient dishwater, waterless steamers, efficient pre-rinse spray valves \\
\hline Intelligent irrigation systems & Installation of timers or programming systems to optimize the irrigation system \\
\hline Vegetation with lower water requirements & Planting native species which are well suited to the climate \\
\hline \multicolumn{2}{|r|}{ Advanced Measures } \\
\hline Installation of submeters by zones & Sub-metering water use in kitchen, rooms, laundry, pool areas, public toilets, or garden \\
\hline Wastewater for irrigation & Reuse of treated grey water from baths and sinks to irrigate \\
\hline Collection and use of rainwater & Harvesting rainwater to be used for laundry, irrigation, or other non-potable uses \\
\hline Reduction of water pressure & Installing pressure reducers, or pressure groups with frequency inverter \\
\hline Leak detection and control of water losses & Periodic inspection of water network using equipment and devices \\
\hline
\end{tabular}

Conversely, we consider "advanced measures" to be those that involve significant technical problems and usually require higher levels of economic investment. We can include in this category: the introduction of water submeters in the different water intensive areas of the hotel, the use of treated waste water for irrigation, collection and use of rainwater, water pressure adjustment, and leak detection and control of water losses.

Based on reference [30] (pp. 519-520), the key features of the model are clarified below. The dependent variable consists of $j=1, \ldots, J$ mutually exclusive categories, which have a natural order. For each case, only one of the categories is observed according to:

$$
y_{i}=j \text { if and only if, } \gamma_{j-1}<y_{i}^{*} \leq \gamma_{j} \quad j=1, \ldots, J
$$

where $\gamma_{j}$ indicates different thresholds, which are unknown, except for $\gamma_{0}=-\infty$ and $\gamma_{J}=\infty$. $y_{i}^{*}$ is a latent variable, which can be specified according to $y_{i}^{*}=x_{i}^{\prime} \beta+u_{i}$. In this application, the latent variable captures the willingness to implement water-saving measures. As the latent variable increases, the number of implemented measures also increases as another threshold is reached. The probability of observing option $j$ is:

$$
\operatorname{Pr}\left(y_{i}=j \mid x_{i}\right)=p_{i j}=F\left(\gamma_{j}-x_{i} \beta\right)-F\left(\gamma_{j-1}-x_{i} / \beta\right) \quad j=1, \ldots, J
$$

where $F(\cdot)$ is an accumulated distribution function, and using the accumulated standard normal distribution function, $\Phi(\cdot)$, implies an Ordered Probit model. It is necessary to estimate $\gamma_{j}, j=1, \ldots, J-1$ thresholds, apart from the parameters, $\beta$. Notice that the latent variable is specified without any constant because otherwise the thresholds are not identified. The absence of the constant does not influence the estimate of the parameters, $\beta$. The model is estimated with maximum likelihood. The sign of the coefficient indicates whether the latent variable increases or decreases with the explanatory variable, but calculating marginal effects is necessary to evaluate how the explanatory variables affect the probabilities of observing each category. The expressions of the marginal effects are straightforward 
to obtain as a derivative of the probability with respect to the variable of interest, or as a discrete change, which is preferred in the case of dummy variables. Notice that each category, $j=1, \ldots, J$, will have its own marginal effects and that $j=1$ indicates not having implemented any water-saving measure of the types that were analyzed (i.e., simple or advanced), while $j=J$ indicates that the hotel has implemented all of the water-saving measures considered. The sign of the marginal effect for the last category will coincide with that of the coefficient, and the marginal effect for the first category will be of the opposite sign, while the sign of the rest of the marginal effects can be either positive or negative. The estimation of the model was performed in Stata, and the marginal effects were obtained with the post estimation command margins.

The dependent variable of the model is the number of water-saving measures incorporated by the hotels. In the case of simple innovations, the dependent variable takes values from 0 (hotels that have not incorporated any water-saving initiatives) to 6 (for those that have incorporated all the initiatives). In the case of advanced innovations, the dependent variables take values from 0 to 5 .

The explanatory variables introduced in the probit regression analysis were selected based on evidence obtained by previous literature, and can be divided into two main groups. First, we include a set of variables related to the physical characteristics of the hotel that can influence the decision to introduce water-saving measures (see Table 2 for a complete resume). The variables related to physical characteristics introduced in the Probit Model are the age of the hotel (we expect that older hotels tend to present higher incentives to modernize their facilities and introduce water-saving initiatives [22,31]), hotel size (larger hotels consume more water in absolute terms $[8,19,32,33]$, however, in terms of per guest night, they can consume less $[16,20,21])$, and the existence of water-intensive facilities and services, such as pools, spa, and laundry facilities [8,31,34].

Table 2. Description of Probit Model explanatory variables.

\begin{tabular}{|c|c|c|c|}
\hline \multicolumn{4}{|c|}{ Variables Related to the Physical Characteristics of the Hotel } \\
\hline & Variable & Expected sign & Reference \\
\hline Age of the hotel & Age & Positive & {$[22,31]$} \\
\hline Hotel size & Number of rooms & Positive & {$[8,19,32,33]$} \\
\hline & Existence of laundry (dummy) & Positive & {$[8,31,34]$} \\
\hline Water intensive facilities & Existence of spa (dummy) & Positive & {$[8,31,34]$} \\
\hline & Pool area & Positive & {$[8,31,34]$} \\
\hline \multicolumn{4}{|c|}{ Variables Related to the Hotel Management System } \\
\hline & Variable & Expected sign & Reference \\
\hline Category & Stars $\geq 4$ (dummy) & Positive & {$[13,15,35]$} \\
\hline Chain affiliation & Chain (dummy) & Positive & [19] \\
\hline
\end{tabular}

Source: own elaboration.

The second group of explanatory variables, related to the hotel management system, includes chain affiliation and the number of stars. Literature shows a positive relationship between water consumption and the hotel category $[13,15,35]$. With respect to chain affiliation, previous evidence demonstrates that affiliation to large international chains is usually related to higher levels of water consumption [19]. Large international chains usually impose a set of standards (i.e., quality standards, levels of cleanliness, bathroom facilities, services, etc.) which can be more water intensive compared to what is found among independent hotels.

\section{Results}

The average consumption per overnight stay in 2015 was 594 L/g.n. in the five-star hotels, 285 L/g.n. in the four-star hotels, 224 L/g.n. in the three-star hotels, and 208 and 247 L/g.n. in the two- and one-star hotels, respectively. As expected, simple water-saving innovations are more widely implemented than advanced innovations. On average, in our sample, hotels had introduced 2.8 simple innovations versus 1.78 advanced innovations (see Table 3). In absolute terms, our sample reveals 
that only $10.17 \%$ of the sample hotels had never introduced simple innovations in their hotel facilities, while in the case of advanced innovations this percentage rises to $18.64 \%$. In the same line, $59.32 \%$ of the sample hotels answered that they had introduced three or more simple innovations, while the percentage in the case of advanced innovations was only $25.42 \%$.

Table 3. Implementation of water-saving measures in the sample.

\begin{tabular}{|c|c|c|c|c|}
\hline Variable & Mean/Proportion & Standard Deviation & Min & Max \\
\hline Simple measures & 2.80 & 1.70 & 0 & 6 \\
\hline Low-flow fittings & 0.66 & 0.48 & 0 & 1 \\
\hline Infrared taps & 0.08 & 0.28 & 0 & 1 \\
\hline Low-flush toilets & 0.64 & 0.48 & 0 & 1 \\
\hline Efficient devices in kitchens & 0.41 & 0.49 & 0 & 1 \\
\hline Intelligent irrigation systems & 0.53 & 0.50 & 0 & 1 \\
\hline Vegetation with lower water requirements & 0.47 & 0.50 & 0 & 1 \\
\hline Advanced measures & 1.78 & 1.40 & 0 & 5 \\
\hline Installation of submeters by zones & 0.32 & 0.47 & 0 & 1 \\
\hline Wastewater for irrigation & 0.10 & 0.30 & 0 & 1 \\
\hline Collection and use of rainwater & 0.17 & 0.38 & 0 & 1 \\
\hline Reduction of water pressure & 0.51 & 0.50 & 0 & 1 \\
\hline Leak detection and control of water losses & 0.46 & 0.50 & 0 & 1 \\
\hline
\end{tabular}

Source: Own elaboration.

Specifically, in the case of simple innovations, the most extended ones are the introduction of low-flow fittings in water devices (66.1\% of all the sample hotels have adopted this measure), followed by low-flush toilets (64.4\%), and the implementation of efficient irrigation systems (53\%). The least frequent simple innovation is the installation of infrared taps (8.5\%).

With respect to the advanced innovations, the most extended one is the introduction of systems of water pressure adjustment (50.8\% of all the hotels in the sample have adopted this measure), followed by the development of systems for leak detection and control of water losses (45.8\%), and the installation of submeters in the water intensive areas (32.2\%). The least popular advanced innovations are the collection and use of rainwater and the use of wastewater for irrigation (with $17 \%$ and $10.2 \%$, respectively). This is understandable to a point since (treated) wastewater may still contain a variety of chemicals [36] and the risk it poses should always be assessed [37].

At this point we analyzed the variables that have influenced the adoption of different types of measures. Marginal effects are calculated from both models, which are more interesting than the coefficients. The significant main variables behind the introduction of simple water-saving initiatives are the existence of laundry facilities and the age of the hotel (Table 4). A similar pattern is found for advanced innovations, where, in addition, the marginal effect for category is also significant, but only in the case of zero measures (Table 5). Each column in the tables corresponds to the number of water-saving innovations implemented. The marginal effect refers to how the probability for that number of innovations changes due to a unit change in the variable, while keeping other variables constant. For dummy variables, a discrete change, i.e., having the characteristic compared to not having it, is used to evaluate the marginal effect.

An additional year since the opening of the hotel reduces the probability of not having implemented any simple water-saving measures by 0.005 . Having a laundry service reduces the probability of not having any simple water-saving innovations by 0.16 , while it increases the probability of having four innovations by 0.16 . Having a laundry service also reduces the probability of not having any advanced water-saving measures by 0.150 , while the probability of having implemented five advanced innovations increases by 0.068 . Hotels with four stars or more were found to have a probability of not having introduced any water-saving innovations that decreased by 0.166 .

Hotel managers were asked about what they considered to be the main drivers that made them introduce water-saving innovations (Table 6). The most popular drivers were cost reduction (36.93\%), followed by environmental concerns $(28.59 \%)$. These results are similar to those obtained in another study carried out in 19 hotels in Girona, Spain [31]. The least common drivers were legal requirements 
(5.24\%) and customer loyalty (5.64\%). These results differ from those obtained by reference [19] in Mallorca, where the main reasons put forward by hotel managers in 2007 to justify the introduction of these initiatives were those related to the hotel's image, quality of service, and customer loyalty, while the cost was less important.

Table 4. Ordered probit regression model for simple water-saving measures.

\begin{tabular}{|c|c|c|c|c|c|c|c|}
\hline \multirow{3}{*}{ Variable } & \multicolumn{7}{|c|}{ Number of Simple Measures } \\
\hline & 0 & 1 & 2 & 3 & 4 & 5 & 6 \\
\hline & $\begin{array}{c}\text { ME } \\
\text { ( } p \text {-Value) }\end{array}$ & $\begin{array}{c}\text { ME } \\
\text { ( } p \text {-Value) }\end{array}$ & $\begin{array}{c}\text { ME } \\
(p-\text { Value })\end{array}$ & $\begin{array}{c}\text { ME } \\
(p-\text { Value })\end{array}$ & $\begin{array}{c}\text { ME } \\
(p-\text { Value) }\end{array}$ & $\begin{array}{c}\text { ME } \\
(p \text {-Value) }\end{array}$ & $\begin{array}{c}\text { ME } \\
(p-\text { Value })\end{array}$ \\
\hline Age & $\begin{array}{c}-0.005 \text { * } \\
(0.022)\end{array}$ & $\begin{array}{c}-0.004 * \\
(0.028)\end{array}$ & $\begin{array}{l}-0.001 \\
(0.090)\end{array}$ & $\begin{array}{c}0.000 \\
(0.780)\end{array}$ & $\begin{array}{l}0.004 * \\
(0.035)\end{array}$ & $\begin{array}{l}0.004 * \\
(0.042)\end{array}$ & $\begin{array}{c}0.003 \\
(0.072)\end{array}$ \\
\hline Rooms & $\begin{array}{c}0.000 \\
(0.986)\end{array}$ & $\begin{array}{c}0.000 \\
(0.986)\end{array}$ & $\begin{array}{c}0.000 \\
(0.986)\end{array}$ & $\begin{array}{c}0.000 \\
(0.986)\end{array}$ & $\begin{array}{c}0.000 \\
(0.986)\end{array}$ & $\begin{array}{c}0.000 \\
(0.986)\end{array}$ & $\begin{array}{c}0.000 \\
(0.986)\end{array}$ \\
\hline $\begin{array}{l}\text { Hotel } \\
\text { chain }\end{array}$ & $\begin{array}{l}-0.004 \\
(0.934)\end{array}$ & $\begin{array}{l}-0.004 \\
(0.933)\end{array}$ & $\begin{array}{l}-0.001 \\
(0.932)\end{array}$ & $\begin{array}{c}0.000 \\
(0.942)\end{array}$ & $\begin{array}{c}0.003 \\
(0.933)\end{array}$ & $\begin{array}{c}0.003 \\
(0.933)\end{array}$ & $\begin{array}{c}0.002 \\
(0.932)\end{array}$ \\
\hline Spa & $\begin{array}{l}-0.007 \\
(0.873)\end{array}$ & $\begin{array}{l}-0.006 \\
(0.874)\end{array}$ & $\begin{array}{l}-0.002 \\
(0.876)\end{array}$ & $\begin{array}{c}0.000 \\
(0.885)\end{array}$ & $\begin{array}{c}0.005 \\
(0.874)\end{array}$ & $\begin{array}{c}0.005 \\
(0.875)\end{array}$ & $\begin{array}{c}0.004 \\
(0.874)\end{array}$ \\
\hline Pool area & $\begin{array}{l}-0.001 \\
(0.330)\end{array}$ & $\begin{array}{l}-0.001 \\
(0.354)\end{array}$ & $\begin{array}{c}0.000 \\
(0.373)\end{array}$ & $\begin{array}{c}0.000 \\
(0.794)\end{array}$ & $\begin{array}{c}0.001 \\
(0.353)\end{array}$ & $\begin{array}{c}0.001 \\
(0.333)\end{array}$ & $\begin{array}{c}0.001 \\
(0.367)\end{array}$ \\
\hline Laundry & $\begin{array}{c}-0.155^{* *} \\
(0.006)\end{array}$ & $\begin{array}{c}-0.180^{* *} \\
(0.005)\end{array}$ & $\begin{array}{c}-0.063 * \\
(0.048)\end{array}$ & $\begin{array}{c}0.010 \\
(0.749)\end{array}$ & $\begin{array}{l}0.161^{* *} \\
(0.005)\end{array}$ & $\begin{array}{l}0.146 \text { * } \\
(0.013)\end{array}$ & $\begin{array}{c}0.082 \\
(0.065)\end{array}$ \\
\hline Stars $(\geq 4)$ & $\begin{array}{l}-0.091 \\
(0.071)\end{array}$ & $\begin{array}{l}-0.079 \\
(0.073)\end{array}$ & $\begin{array}{l}-0.025 \\
(0.126)\end{array}$ & $\begin{array}{c}0.007 \\
(0.633)\end{array}$ & $\begin{array}{c}0.072 \\
(0.087)\end{array}$ & $\begin{array}{c}0.071 \\
(0.090)\end{array}$ & $\begin{array}{c}0.046 \\
(0.110)\end{array}$ \\
\hline
\end{tabular}

Note: Each column indicates the marginal effect on the probability of having implemented the number of simple water-saving measures as indicated in the label of the column (0-6). The variable 'rooms' is measured in tens in the model, and the marginal effect (ME) is interpreted as how an increase of 10 units in the variable would affect the probability, keeping other variables constant. Pool area is also measured in tens, and interpreted in the same way, while the rest of the variables are kept in their original scale. ${ }^{* *}$ significant at $1 \%$, * significant at $5 \%$. Source: Own elaboration.

Table 5. Ordered probit regression model for advanced measures.

\begin{tabular}{|c|c|c|c|c|c|c|}
\hline \multirow{3}{*}{ Variable } & \multicolumn{6}{|c|}{ Number of Advanced Measures } \\
\hline & 0 & 1 & 2 & 3 & 4 & 5 \\
\hline & $\begin{array}{c}\text { ME } \\
(p \text {-Value) }\end{array}$ & $\begin{array}{c}\text { ME } \\
(p \text {-Value) }\end{array}$ & $\begin{array}{c}\text { ME } \\
(p \text {-Value) }\end{array}$ & $\begin{array}{c}\text { ME } \\
(p \text {-Value) }\end{array}$ & $\begin{array}{c}\text { ME } \\
(p-\text { Value })\end{array}$ & $\begin{array}{c}\text { ME } \\
(p-\text { Value })\end{array}$ \\
\hline \multirow{2}{*}{ Age } & -0.006 & -0.003 & 0.002 & 0.003 & 0.002 & 0.003 \\
\hline & $(0.063)$ & $(0.095)$ & $(0.144)$ & $(0.096)$ & $(0.160)$ & $(0.101)$ \\
\hline \multirow{2}{*}{ Rooms } & 0.004 & 0.002 & -0.001 & -0.002 & -0.001 & -0.002 \\
\hline & $(0.255)$ & $(0.252)$ & $(0.310)$ & $(0.262)$ & $(0.301)$ & $(0.275)$ \\
\hline \multirow{2}{*}{ Hotel chain } & -0.076 & -0.028 & 0.026 & 0.031 & 0.017 & 0.031 \\
\hline & $(0.406)$ & $(0.317)$ & $(0.446)$ & $(0.392)$ & $(0.403)$ & $(0.356)$ \\
\hline \multirow{2}{*}{ Spa } & -0.072 & -0.037 & 0.022 & 0.034 & 0.020 & 0.034 \\
\hline & $(0.286)$ & $(0.354)$ & $(0.327)$ & $(0.338)$ & $(0.382)$ & $(0.316)$ \\
\hline \multirow{2}{*}{ Pool area } & -0.004 & -0.002 & 0.001 & 0.002 & 0.001 & 0.002 \\
\hline & $(0.083)$ & $(0.112)$ & (0.189) & $(0.115)$ & (0.154) & $(0.113)$ \\
\hline \multirow{2}{*}{ Laundry } & -0.150 * & -0.076 & 0.048 & 0.071 & 0.040 & 0.068 \\
\hline & $(0.026)$ & $(0.071)$ & (0.099) & $(0.074)$ & $(0.154)$ & $(0.061)$ \\
\hline \multirow{2}{*}{ Stars $(\geq 4)$} & $-0.166^{*}$ & -0.080 & 0.060 & 0.079 & 0.042 & 0.065 \\
\hline & $(0.031)$ & $(0.072)$ & (0.119) & $(0.060)$ & $(0.142)$ & $(0.071)$ \\
\hline
\end{tabular}

Note: Each column indicates the marginal effect on the probability of having implemented the number of advanced water-saving measures indicated in the label of the column $(0-5)$. The variable 'rooms' is measured in tens in the model, and the marginal effect (ME) is interpreted as how a 10-unit increase in the variable would affect the probability, keeping other variables constant. Pool area is also measured in tens, and interpreted in the same way, while the rest of the variables are kept in their original scale. ${ }^{* *}$ significant at $1 \%$, * significant at $5 \%$. Source: Own elaboration. 
Table 6. Descriptive statistics for the drivers of the introduction of water-saving measures.

\begin{tabular}{clccc}
\hline Drivers & Mean & Standard Deviation & Min & Max \\
\hline Cost reduction & 36.94 & 31.92 & 0 & 100 \\
Customer loyalty & 5.65 & 8.80 & 0 & 40 \\
Hotel image & 8.99 & 11.06 & 0 & 50 \\
Environmental concerns & 28.59 & 28.43 & 0 & 100 \\
Tour operators' requirements & 5.77 & 15.46 & 0 & 10 \\
Chain requirements & 6.41 & 12.65 & 0 & 50 \\
Legal requirements & 5.25 & 15.08 & 0 & 100 \\
Other drivers & 0.42 & 2.16 & 0 & 12.5 \\
\hline
\end{tabular}

Source: Own elaboration.

The survey question that was used to obtain Table 6 is B4, which can be found in Supplementary Materials (S1). It is continuous sum question for percentages, which means that the declared percentages for the drivers must sum to 100 for all respondents. Table 6 includes the average of the declared percentages for that specific driver. Some of the reasons are related to externally defined criteria, for example, hotel chains and tour operators can have environmental specifications or quality standards that should be fulfilled. Legal specifications are another kind of externally defined criteria.

\section{Discussion}

The implementation of water-saving measures in hotels can be an effective instrument to reduce levels of water consumption, and can lead to substantial improvements in water resources. A review of the literature shows that water savings of between $20 \%$ and $50 \%$ are possible in many hotels $[11-13,22,24,26-29]$ and highlights the need for further research on this topic. This is particularly important in those areas where water scarcity is significant $[15,26]$, as in the Mediterranean region, which is highly vulnerable to climate change [38] and where much of the tourism is concentrated. This research provides new evidence of the level of implementation of water-saving measures in hotels of one of the main tourist destinations in the Mediterranean Sea, the island of Mallorca.

Concretely, this study shows that simple water-saving measures are the most implemented, in line with other studies $[31,39,40]$. Cost savings of applying this kind of measures can be important. For example, with a low-cost program in 20 Jamaican hotels, it was possible to improve water use efficiency by $30 \%$ and obtain a saving in operating costs of $\$ 800 /$ room/year. The measures included in the program were water monitoring, basic maintenance of plumbing fixtures, basic maintenance of pipes and equipment, staff training and motivation, and a towel and linen reuse program [28]. Through a similar project of retrofitting guestrooms in a three-star hotel in Malta with simple low-cost measures (low-flow aerators and shower heads, volume displacers in toilet cisterns), reference [23] showed a reduction in water consumption of $48 \%$ per overnight stay and a profitability of $1650 \%$. In a hotel in the city of Zaragoza (Spain), [29] also showed how retrofitting with water-saving devices in guest bathrooms and toilets, washrooms in public areas, and the kitchen can reduce the water consumption by $21.5 \%$ and be very profitable both financially (for hotels) and economically (for the whole of society), with minimum returns of $1233 \%$ and $932 \%$, respectively.

These examples explain why the cost incentive is the main driver leading hoteliers to implement water-saving measures $[20,31,35,41,42]$. In our sample, the most popular drivers was cost reduction, followed by environmental concerns. These results are similar to those obtained in another study carried out in 19 hotels in Girona, Spain [31] or by reference [22] for a sample of 53 hotels on the Costa Brava (Spain), where the main drivers behind the introduction of water-saving initiatives are the reduction in water cost, and a higher level of environmental concern by hotel managers. In this latest study, the most proactive hotels and those that apply the most measures are large high-category hotels, because they offer many water-related services (swimming pools, laundry, green areas, etc.). Within these, the most proactive and most technified hotels are old hotels that have reformed and modernized their facilities. 
In our case, results confirm that the age, the existence of laundry facilities, and the category play a significant role, in accordance with the results obtained by previous studies $[8,22,28,34]$. With respect to the age of the hotel, the oldest hotels display a more proactive attitude to the introduction of water-saving innovations in hotel facilities. Most of the Mallorca hotel plant was built during the sixties and seventies. During those years the presence of water-saving techniques in hotels was very rare, for a variety of reasons, ranging from technical reasons (with scarce development) to economic motives (low water prices and, thus, low water costs), and social reasons (low level of awareness about environmental issues). These factors, together, explain why the majority of the hotels built in the early years of the development of tourism were characterized by high water consumption, and with significant inefficiency indicators. In contrast, in recent years the changes that have taken place in water prices, environmental concerns, and technological development in the water sector have led many hotel companies to introduce innovations in their water management systems.

The results also confirm that hotel category is a significant factor to explain their predisposition to introduce water-saving measures. Hotels in a higher category are more active in the introduction of water-saving innovations. It seems that hotels in higher categories tend to have higher levels of water consumption due to their higher quality standards, and the services and facilities offered [22,35]. These hotels therefore have higher water costs, which increases the incentives to incorporate water-saving innovations. Thus, two opposing effects appear between the conservation measures and the increase in water-related services and amenities in hotels [21]. Higher category hotels can apply water-saving measures, but at the same time require more or better water-related amenities.

In our study, the existence of on-site laundry facilities pushes hotel companies to introduce both simple and advanced water-saving innovations. Laundry facilities are one of the areas where more water is consumed in hotels. Previous studies confirm this fact [8]. Based on a sample of Hong Kong hotels, reference [34] concludes that an on-site laundry constitutes the highest area of water consumption, and accounts for $47 \%$ of the total hotel water consumption. Similarly, the study by reference [28] determines that laundry facilities represent, on average, $20 \%$ of the total hotel water consumption. In the same context, reference [43] (pp. 108-124) found that the average consumption in an average three-star hotel in France is $12 \%$ of the total hotel water consumption, and is the fourth highest water consuming facility in the hotel.

\section{Conclusions}

This study provides evidence showing that hotels in the three representative municipalities in Mallorca have been proactive in introducing water-saving measures. Based on a survey carried out in 59 hotels on the island, we determined that $59.32 \%$ of the sample hotels had introduced three or more simple innovations and $25.42 \%$ had introduced three or more advanced innovations. In the most common categories in the sample, i.e., four-star and three-star hotels, the average consumption per overnight stay is $285 \mathrm{~L} / \mathrm{g} . \mathrm{n}$. and $224 \mathrm{~L} / \mathrm{g} . \mathrm{n}$., respectively, and this is not far from the suggested benchmarks offered by the literature. However, there is still room to reduce the levels of the water consumption of hotels. For example, the literature shows that it is possible to reach a hotel water consumption of 140 L/g.n. in mid-range fully serviced European hotels [12], or 300-400 L/g.n. in five-star hotels $[13,44]$.

Our analysis concludes that hotels prefer to introduce simple water-saving measures, and that the main variables that influence the implementation are the existence of laundry facilities, the age of the hotel, and the number of stars. The same variables were also relevant for the advanced water-saving measures. Our results confirm that the higher category hotels, which normally offer services that consume large amounts of water, are more likely to implement such measures, since the cost savings can be considerable. The average consumption per overnight stay in this kind of hotel, $594 \mathrm{~L} / \mathrm{g} . \mathrm{n}$. , reveals that it is possible to continue reducing water consumption. Fortunately, the new water-saving technologies incorporated into the water devices available in the market (faucets, toilets, etc.) make 
it possible for older hotels to include these saving devices when they carry out the renovation and modernization of their facilities, regardless of the category of the hotels.

The main driver argued by hotel managers for the implementation of water-saving innovations was the cost reduction, followed by environmental concerns. Thus, it seems that these drivers have changed since the year 2007, when other studies in Mallorca showed that marketing and image were the main drivers why hotels introduced water-saving innovations, while the cost of water was less important $[19,45]$. This change could be explained by the significant increase in the price of water over this period (34\%).

The interviews with the hotel managers reveal the lack of knowledge (especially in small and medium-sized hotels) regarding the use and management of water in their establishment, and the water and cost savings that can be achieved through the implementation of best practices or retrofitting with water-saving measures $[15,31,46]$. This lack of knowledge is one of the main barriers to the implementation of water-saving measures [22]. Thus, it is essential that hotel managers are well informed about the water-saving innovations available for their hotel [35]. In order to extend the application of such measures, we encourage public entities and hotel associations to develop campaigns to provide more detailed information about the economic, financial and environmental benefits that could be achieved by adopting the different types of water-saving measures available.

On the other hand, the high investment costs of advanced measures tend to hinder their application. For example, only $10.2 \%$ of the hotels in the sample use wastewater for irrigation and $17 \%$ collect and use rainwater. In this context, the public administration could play a more active role by implementing tax incentives to promote the adoption of these kinds of measures.

According to the results obtained, there is scope to implement measures that involve having additional water, which does not come from the municipal supply network. The collection and use of rainwater, as well as the reuse and the recycling of gray water are advanced measures that could achieve a more sustainable use of water resources and provide significant water and cost savings for hotels [47]. Both the hotel sector and the administration itself should work together to make the hotel industry a benchmark in sustainable water management.

Supplementary Materials: The following are available online at http://www.mdpi.com/2071-1050/11/23/6880/s1. The survey question that was used to get the data from the hotels can be found as S1.

Author Contributions: Conceptualization, D.T., W.N., B.D.-T. and C.G.; investigation, D.T.; methodology, W.N.; formal analysis, W.N. and B.D.-T.; writing — original draft preparation, D.T and B.D.-T.; editing and writing C.G.

Funding: This research received no external funding.

Acknowledgments: This research did not receive any specific grant from funding agencies in the public, commercial, or not-for-profit sectors. Comments made by the reviewers improved the final version of the manuscript.

Conflicts of Interest: The authors declare no conflict of interest.

\section{References}

1. World Tourism Organization (UNWTO). International Tourism Highlights, 2019 Edition; World Tourism Organization (UNWTO): Madrid, Spain, 2019.

2. World Tourism Organization (UNWTO). Tourism Towards 2030/Global Overview; World Tourism Organization: Madrid, Spain, 2011.

3. Shang, J.; Basil, D.Z.; Wymer, W. Using social marketing to enhance hotel reuse programs. J. Bus. Res. 2010, 63, 166-172. [CrossRef]

4. Kent, M.; Newnham, R.; Essex, S. Tourism and sustainable water supply in Mallorca: A geographical analysis. Appl. Geogr. 2002, 22, 351-374. [CrossRef]

5. Essex, S.; Kent, M.; Newnham, R. Tourism Development in Mallorca: Is Water Supply a Constraint? J. Sustain. Tour. 2004, 12, 4-28. [CrossRef]

6. World Tourism Organization (UNWTO). Tourism in the Green Economy—Background Report; The World Tourism Organization (UNWTO) and United Nations Environment Programme (UNEP): Madrid, Spain, 2012. 
7. World Water Assessment Programme. The United Nations World Water Development Report 3: Water in a Changing World; World Water Assessment Programme: Paris, France, 2009.

8. Gössling, S. The consequences of tourism for sustainable water use on a tropical island: Zanzibar, Tanzania. J. Environ. Manag. 2001, 61, 179-191. [CrossRef]

9. Giulietti, S.; Romagosa, F.; Esteve, F.; Schröder, C. Tourism and the Environment. Towards a Reporting Mechanism in Europe; European Topic Centre on Urban Land and Soil Systems: Bellatera, Spain, 2018.

10. Holden, A. Environment and Tourism; Routledge: New York, NY, USA, 2016.

11. Kasim, A.; Gursoy, D.; Okumus, F.; Wong, A. The importance of water management in hotels: A framework for sustainability through innovation. J. Sustain. Tour. 2014, 22, 1090-1107. [CrossRef]

12. Styles, D.; Schoenberger, H.; Galvez-Martos, J.L. Water management in the European hospitality sector: Best practice, performance benchmarks and improvement potential. Tour. Manag. 2015, 46, 187-202. [CrossRef]

13. Hamele, H.; Eckardt, E. Environmental Initiatives by European Tourism Businesses. Instruments, Indicators and Practical Examples. A Contribution to the Development of Sustainable Tourism in Europe; ECOTRANS e.V.: Saarbrücken, Germany, 2006.

14. International Tourism Partnership Environmental Management for Hotels: The Industry Guide to Sustainanble Operation. Available online: https://www.greenhotelier.org/our-manuals/environmentalmanagement-for-hotels/chapter-3-water/ (accessed on 24 November 2019).

15. Charara, N.; Cashman, A.; Bonnell, R.; Gehr, R. Water use efficiency in the hotel sector of Barbados. J. Sustain. Tour. 2011, 19, 231-245. [CrossRef]

16. Mclennan, C.J.; Becken, S.; Stinson, K. A Water-Use Model For The Tourism Industry In The Asia-Pacific Region: The Impact Of Water-Saving Measures On Water Use. J. Hosp. Tour. Res. 2017, 41, 746-767. [CrossRef]

17. IBESTAT Dades Població. Available online: https://ibestat.caib.es/ibestat/estadistiques/poblacio (accessed on 24 November 2019).

18. Garcia, C.; Servera, J. Impacts of tourism development on water demand and beach degradation on the island of Mallorca (Spain). Geogr. Ann. 2003, 85, 287-300. [CrossRef]

19. Deyà Tortella, B.; Tirado, D. Hotel water consumption at a seasonal mass tourist destination. The case of the island of Mallorca. J. Environ. Manag. 2011, 92, 2568-2579. [CrossRef]

20. Gabarda-Mallorquí, A.; Garcia, X.; Ribas, A. Mass tourism and water efficiency in the hotel industry: A case study. Int. J. Hosp. Manag. 2017, 61, 82-93. [CrossRef]

21. Rico, A.; Olcina, J.; Baños, C.; Garcia, X.; Sauri, D. Declining water consumption in the hotel industry of mass tourism resorts: Contrasting evidence for Benidorm, Spain. Curr. Issues Tour. 2019, 1-14. [CrossRef]

22. Gabarda-Mallorquí, A.; Ribas Palom, A. Exploración de tipologías hoteleras según el nivel de implementación de medidas de ahorro hídrico a través de un análisis cluster. El caso de Lloret de Mar (Costa Brava). Cuad. Tur. 2018, 41, 187-218. [CrossRef]

23. Gatt, K.; Schranz, C. Retrofitting a 3 star hotel as a basis for piloting water minimisation interventions in the hospitality sector. Int. J. Hosp. Manag. 2015, 50, 115-121. [CrossRef]

24. Chan, E.S.W.; Okumus, F.; Chan, W. The Applications of Environmental Technologies in Hotels. J. Hosp. Mark. Manag. 2017, 26, 23-47. [CrossRef]

25. Trung, D.N.; Kumar, S. Resource use and waste management in Vietnam hotel industry. J. Clean. Prod. 2005, 13, 109-116. [CrossRef]

26. Warren, C.; Becken, S. Saving energy and water in tourist accommodation: A systematic literature review (1987-2015). Int. J. Tour. Res. 2017, 19, 289-303. [CrossRef]

27. Meade, B.; Pringle, J. Environmental Management Systems for Caribbean Hotels and Resorts. J. Qual. Assur. Hosp. Tour. 2001, 2, 149-159. [CrossRef]

28. Meade, B.; Gonzalez-Morel, P. Improving Water Use Efficiency in Jamaican Hotels and Resorts Through the Implementation of Environmental Management Systems. J. Contemp. Water Res. Educ. 2011, 115, $39-45$.

29. Barberán, R.; Egea, P.; Gracia-de-Rentería, P.; Salvador, M. Evaluation of water saving measures in hotels: A Spanish case study. Int. J. Hosp. Manag. 2013, 34, 181-191. [CrossRef]

30. Cameron, A.C.; Trivedi, P.K. Microeconometrics: Methods and Applications; Cambridge University Press: New York, NY, USA, 2005. 
31. Torres-Bagur, M.; Ribas, A.; Vila-Subirós, J. Incentives and Barriers to Water-Saving Measures in Hotels in the Mediterranean: A Case Study of the Muga River Basin (Girona, Spain). Sustainability 2019, 11, 3583. [CrossRef]

32. Bohdanowicz, P.; Martinac, I. Determinants and benchmarking of resource consumption in hotels-Case study of Hilton International and Scandic in Europe. Energy Build. 2007, 39, 82-95. [CrossRef]

33. Gopalakrishnan, C.; Cox, L.J. Water Consumption by the Visitor Industry: The Case of Hawaii. Int. J. Water Resour. Dev. 2003, 19, 29-35. [CrossRef]

34. Deng, S.-M.; Burnett, J. Water use in hotels in Hong Kong. Int. J. Hosp. Manag. 2002, 21, 57-66. [CrossRef]

35. Dinarès, M.; Saurí, D. Water consumption patterns of hotels and their response to droughts and public concerns regarding water conservation: The case of the Barcelona hotel industry during the 2007-2008 episode. Documents d'anàlisi geogràfica 2015, 61, 623. [CrossRef]

36. Sonavane, M.; Schollée, J.E.; Hidasi, A.O.; Creusot, N.; Brion, F.; Suter, M.J.-F.; Hollender, J.; Aït-Aïssa, S. An integrative approach combining passive sampling, bioassays, and effect-directed analysis to assess the impact of wastewater effluent. Environ. Toxicol. Chem. 2018, 37, 2079-2088. [CrossRef]

37. Kungolos, A.; Emmanouil, C.; Manakou, V.; Darakas, E. Assessment of vulnerable freshwater ecosystems and various aquatic effluents by means of ecotoxicological assays. Desalin. Water Treat. 2015, 54, 2120-2129. [CrossRef]

38. Cramer, W.; Guiot, J.; Fader, M.; Garrabou, J.; Gattuso, J.-P.; Iglesias, A.; Lange, M.A.; Lionello, P.; Llasat, M.C.; $\mathrm{Paz}, \mathrm{S}$; ; et al. Climate change and interconnected risks to sustainable development in the Mediterranean. Nat. Clim. Chang. 2018, 8, 972-980. [CrossRef]

39. Bruns-Smith, A.; Choy, V.; Chong, H.; Verma, R. Environmental Sustainability in the Hospitality Industry: Best Practices, Guest Participation, and Customer Satisfaction. Center Hospitality Research Publications 2015. Available online: https://scholarship.sha.cornell.edu/cgi/viewcontent.cgi? article=1199\&context=chrpubs (accessed on 3 December 2019).

40. Han, H.; Hyun, S.S. What influences water conservation and towel reuse practices of hotel guests? Tour. Manag. 2018, 64, 87-97. [CrossRef]

41. Razumova, M.; Rey-Maquieira, J.; Lozano, J. The role of water tariffs as a determinant of water saving innovations in the hotel sector. Int. J. Hosp. Manag. 2016, 52, 78-86. [CrossRef]

42. Chan, E.S.W.; Hawkins, R. Attitude towards EMSs in an international hotel: An exploratory case study. Int. J. Hosp. Manag. 2010, 29, 641-651. [CrossRef]

43. Dworak, T.; Berglund, M.; Laaser, C. EU Water Saving Potential (Part. 1-Report)|Ecologic Institute: Science and Policy for a Sustainable World; Ecologic, Institute for International and European Environmental Policy: Berlin, Germany, 2007.

44. Gautam, S.; Ahmed, S.; Ahmed, K.; Haleem, A. Development of water consumption benchmark for five star hotels using Delphi's technique. Water Util. J. 2016, 13, 47-56.

45. Deyà-Tortella, B.; Garcia, C.; Nilsson, W.; Tirado, D. The effect of the water tariff structures on the water consumption in Mallorcan hotels. Water Resour. Res. 2016, 52, 6386-6403. [CrossRef]

46. Kasim, A. Managerial attitudes towards environmental management among small and medium hotels in Kuala Lumpur. J. Sustain. Tour. 2009, 17, 709-725. [CrossRef]

47. Atanasova, N.; Dalmau, M.; Comas, J.; Poch, M.; Rodriguez-Roda, I.; Buttiglieri, G. Optimized MBR for greywater reuse systems in hotel facilities. J. Environ. Manag. 2017, 193, 503-511. [CrossRef] [PubMed]

(C) 2019 by the authors. Licensee MDPI, Basel, Switzerland. This article is an open access article distributed under the terms and conditions of the Creative Commons Attribution (CC BY) license (http://creativecommons.org/licenses/by/4.0/). 